\title{
Representações de mães sobre hospitalização do filho prematuro
}

\author{
Representations of mothers about the hospitalization of their premature child \\ Representaciones de las madres sobre la hospitalización del hijo prematuro
}

\section{Nilba Lima de Souza', Ana Cristina Pinheiro Fernandes Araújo', Íris do Céu Clara Costa', Jovanka Bittencourt Leite de Carvalho', Maria de Lourdes Costa da Silval"}

'Universidade Federal do Rio Grande do Norte. Programa de Pós-Graduação do Centro de Ciências da Saúde. Natal, RN "Universidade Federal do Rio Grande do Norte. Maternidade Escola Januário Cicco. Natal, RN

Submissão: 12/12/2008

Aprovação: 10/08/2009

\section{RESUMO}

Estudo Qualitativo Que objetivou conhecer as representações de mães sobre a hospitalização do filho prematuro na Unidade de Terapia Intensiva Neonatal (UTIN). Inclui dezoito mães de prematuros internados na UTIN de um hospital escola em Natal (RN). Utilizou-se a entrevista semi-estruturada e na análise dos dados evidenciou-se que a hospitalização do filho é representada pelas mães por significados, sentimentos, dificuldades e incertezas. Considera-se que a prematuridade representa um desafio materno desde o momento da constatação do parto pré-termo, prosseguindo com os percalços inerentes a hospitalização e requer conhecimento, escuta e diálogo dos profissionais de saúde de forma efetiva para fortalecimento da adeQuação materna a prematuridade.

Descritores: Comportamento materno; Nascimento prematuro; Enfermagem neonatal; Unidades de terapia intensiva neonatal.

\begin{abstract}
Qualitative study aimed at knowing the representations of mothers about the hospitalization of their premature son in a Neonatal Intensive Care Unit (NICU). The sample was composed of eighteen mothers of premature newborns hospitalized in a school hospital in Natal, Brazil. A semi-structured interview was used and data analysis showed that hospitalization of a child is represented by the mothers as meanings, feelings, difficulties and uncertainties. It is considered that prematurity represents a maternal challenge from the moment of the premature birth, proceeding with disturbances inherent to hospitalization. These require awareness, listening and dialogue on the part of health professionals in an effective manner in order to strengthen maternal adaptation to prematurity.
\end{abstract}

Descriptors: Maternal behavior; Premature birth; Neonatal nursing; Intensive care units, neonatal.

\section{RESUMEN}

Estudio cualitativo con el objeto de conocer las representaciones maternas sobre la hospitalización del hijo prematuro en una Unidad de Terapia Intensiva Neonatal (UTIN). Muestra de dieciocho madres de prematuros internados en la UTIN de un hospital clínico en Natal (RN). Utiliza entrevista semi-estructurada. Los datos constatan que la hospitalización del hijo supone para las madres significados, sentimientos, dificultades e incertidumbres. El parto prematuro representa un reto para la madre desde el momento de la constatación del parto pre-término, continúa con los percances inherentes la hospitalización y requiere conocimiento, escucha y diálogo por parte de los profesionales de salud con el fin de preparar a la madre para dicho parto prematuro.

Descriptores: Conducta materna; Nacimiento prematuro; Enfermería neonatal; Unidades de terapia intensiva neonatal. 


\section{INTRODUÇÃO}

O nascimento prematuro, aquele verificado antes de 37 semanas completas de gestação, apresenta altos índices de morbidade e letalidade perinatal. Atualmente, procedimentos mais especializados, o uso das tecnologias e o modo como a assistência está sendo prestada tem contribuído para um aumento da sobrevida de neonatos pré-termos ${ }^{(1)}$, oferecendo subsídios para o atendimento, cada vez mais especializado, dos aspectos biológicos dos recémnascidos em Unidade de Terapia Intensiva Neonatal (UTIN).

No entanto, a hospitalização de um filho prematuro na UTIN é uma situação Que pode gerar danos emocionais para toda família, principalmente para a mãe, por tratar-se de um ambiente assustador Que inibe o contato espontâneo entre mãe e filho. Ao vivenciar a hospitalização de um filho na UTIN as mães adentram em uma nova realidade, permeada, Quase sempre, por momentos difíceis, Que geram tristeza, dor e desesperança ${ }^{(2)}$. Comumente, o prolongamento da permanência hospitalar desses neonatos, desperta nos pais sentimentos de ansiedade, insegurança e culpa ${ }^{(3)}$.

Algumas unidades neonatais, com vistas a reduzir o impacto causado pelo internamento do filho na UTIN, dentro do processo da humanização da assistência hospitalar, buscam atender as necessidades emocionais de pais de prematuros com uma tendência à valorização dos aspectos subjetivos do processo cuidar. Nesse sentido, considera-se de Qualidade a assistência neonatal cujo cuidado está focalizado não apenas no recém-nascido, mas também centrado na família ${ }^{(4)}$. Trabalhar nessa perspectiva não é fácil, visto Que implica na necessidade de saber lidar repentinamente com emoções fortes ${ }^{(5)}$.

Portanto, entende-se Que o contexto do nascimento prematuro é amplo e exige atenção especializada. Para Scochi(6) a busca da compreensão da vulnerabilidade social da prematuridade agregar não apenas os fatores de risco fisiológicos, mas dimensões sociais, políticas e institucionais.

Assim sendo, contextualizando a participação materna como acompanhante de um filho prematuro na UTIN, observa-se Que vários fatores estão presentes nessa trajetória. Inicialmente, com o nascimento prematuro, as mães vivenciam a Quebra do simbolismo social Que representa a maternidade como ato soberano. SeQüencialmente a hospitalização do filho na UTIN, exige da mulher o afastamento do convívio familiar e a submissão a uma rotinização hospitalar estressante com constatação diária de procedimentos dolorosos e invasivos que compõe a assistência ao neonato e, durante todo esse processo, os sentimentos de medos inseguranças e incertezas Quanto à sobrevivência do filho.

Nessa abordagem, parte-se do pressuposto de que as mães de prematuros demandam cuidados especiais, e, portanto, torna-se imprescindível conhecer os aspectos emocionais e sociais vivenciados por elas com a hospitalização do filho prematuro na UTIN na tentativa de oferecer suporte para o desempenho do papel materno nas unidades neonatais. Diante do exposto, construímos esse estudo com o objetivo de identificar as representações de mães sobre a hospitalização do filho prematuro na UTIN e descrever as dificuldades por elas vivenciadas durante a permanência como mães acompanhantes.

\section{METODOLOGIA}

Estudo de abordagem Qualitativa, tendo como foco a representação de mães sobre sua vivência durante a hospitalização do filho prematuro na UTIN.

Foram entrevistadas onze mulheres Que tiveram parto pré-termo e Que se encontravam há mais de 48 horas com o filho internado em UTIN. O contexto da investigação foi um hospital público de referência estadual para gravidez e nascimento de risco no Rio Grande do Norte.

O trabalho de campo foi realizado nos meses de junho a agosto de 2008 e foi utilizado como instrumento de pesQuisa a entrevista em profundidade na busca de compreensão da realidade social através de significados e atitudes ${ }^{(7)}$ tendo como ponto de partida a seguinte Questão norteadora: o Que representa para você a hospitalização de seu filho prematuro na UTIN.

Os relatos maternos foram transcritos considerando situação sócio-demográfica relevantes aos objetivos da pesquisa. O corpus para análise foi constituído a partir das entrevistas e tratados para categorização sob a ótica da análise de conteúdo preconizada na modalidade análise temática categorial, preconizada por Bardin $^{(8)}$ através das seguintes etapas: pré-análise, exploração do material e tratamento dos resultados. Os conteúdos foram lidos e analisados por dois investigadores Que destacaram os três núcleos temáticos desse estudo: dificuldades maternas com a hospitalização do filho na UTIN, o desafio do cuidado materno na UTIN e os sentimentos maternos vivenciados durante a hospitalização do filho na UTIN seguidos de suas respectivas representações.

Esse estudo teve aprovação do Comitê de Ética em Pesquisa (CEP) - UFRN sob o no 195/06. Foi assegurado o caráter voluntário e anonimato da pesquisa e o termo de consentimento livre e esclarecido foi lido e assinado por todas as participantes.

\section{RESULTADOS E DISCUSSÃO}

As mulheres entrevistadas tinham idade entre 18 e 30 anos e para $80,3 \%$ a escolaridade correspondia ao ensino médio e fundamental e 19,7\% concluíram o ensino superior. A renda familiar mínima predominante foi em torno de um salário mínimo para 71\% das entrevistadas.

No Que se refere aos dados obstétricos e perinatais $78 \%$ das mulheres compareceram em torno de Quatro consultas pré-natais enquanto Que as outras registravam apenas duas consultas. Para $18 \%$ das mulheres o parto ocorreu entre 26-32 semanas de gestação enQuanto Que as demais aconteceram entre 33-36 semanas. Foram registradas intercorrências na gravidez em 22\% das entrevistas a partir do segundo semestre com relato de infecção urinária e hipertensão gestacional. A maior parte das entrevistadas $(71,8 \%)$ era primigesta.

A categorização permitiu a construção dos seguintes núcleos temáticos: Dificuldades maternas com a hospitalização do filho na UTIN; o desafio do cuidado materno na UTIN e, os sentimentos maternos vivenciados durante a hospitalização do filho na UTIN Que serão apresentadas a seguir:

\section{Dificuldades maternas com a hospitalização do filho na UTIN}

\section{Representações sobre a hospitalização do filho}

Percebe-se Que mesmo sabendo Que o parto acontecerá de forma prematura à mulher mantém a esperança de Que o filho nasça com 
boa vitalidade e possa permanecer com ela. Após o nascimento do filho, a mãe espera iniciar trocas interativas e de comunicação com seu bebê $\hat{~}^{(9)}$. Entretanto, ao saber Que ele requer internamento, à idealização do papel materno de realizar cuidados com a criança encontra-se prejudicada e o sonho de ter seu filho no colo e de levá-lo para casa é desfeito(2)

Essa situação foi evidenciada pelas depoentes Quando na concretização da hospitalização do filho na UTIN, revelam a Quebra do simbolismo de parir e não ter o filho nos braços e pelo afastamento imposto devido ao uso de equipamentos neonatais e tratamentos aos Quais os filhos estão submetidos. O discurso a seguir revela os sentimentos com o rompimento da construção inicial do vínculo materno com o filho:

"Nesse momento eu me senti péssima, porque no meu pensava Que ela ia nascer prematura, mas ia ficar perto de mim, não ia precisar separa assim. Como hoje ta fazendo oito dias que ela nasceu e eu ainda não peguei ela no colo. É triste”. (Rosa).

A expectativa de ter filhos perfeitos e saudáveis é comum para todos os pais ${ }^{(10)}$, o Que não foi diferente para as mães participantes dessa pesquisa na Qual o nascimento de um filho prematuro, em condições Que impliQuem em hospitalização, representou a ruptura na dinâmica do nascimento de ter um bebê saudável e poder leválo para casa poucos dias após o nascimento.

\section{Representações da permanência como mãe-acompanhante}

A permanência materna como acompanhante do filho submete a mulher a uma desintegração temporária do convívio familiar e social. Essa situação é ainda mais conflitante Quando na existência de outros filhos, pois as mães se vêem obrigada a adotarem estratégias que comumente consiste em transferir a responsabilidade de cuidar dos filhos menores a outros membros da família. Tal fato pode desencadear sensações de negligenciamento no seu papel de mãe, Que sem escolhas, permanecem acompanhando o filho prematuro e submete os outros filhos a privação dos cuidados maternos. Essa realidade é observada no relato seguinte:

“A gente sabe que precisa ficar aqui porque eles estão doentes, eles precisam da mãe para dar aQuela força, dar carinho, ficar perto, mas a gente se preocupa com os que estão em casa lá abandonados Que também precisam da gente e, como fica a cabeça da mãe numa hora dessa sendo só um pessoa e precisando está em dois lugares ao mesmo tempo?" (Amélia).

Percebe-se no discurso acima Que os conflitos existentes Quanto ao desempenho do papel materno precisa ser dividido entre ser mãe acompanhante e as responsabilidades domiciliares de provedora da coesão familiar, gerando sensações de descontrole sobre a situação e a vivência de sentimentos de impotência irresponsabilidade e negligenciamento. A hospitalização pode deixar implícita a ruptura da estrutura familiar momentânea ou definitivamente, testando o grau de sustentabilidade dos vínculos afetivos e sociais ${ }^{(1)}$.

\section{O desafio do cuidado materno na UTIN}

Representações do cuidado com o filho na UTIN
Ao longo da internação, à medida Que o bebê apresenta melhora clínica, a mãe passa a participar dos cuidados com o filho através da higienização no leito, a dieta por sonda, o tocar, para algumas o segurar no colo, mesmo que por curtos períodos. Essas atividades parecem representar para as mães a reestruturação do papel materno de alimentar os filhos e estabelece a autoconfiança de Que as dificuldades serão vencidas, conforme relato seguinte:

"Foi nesse momento que eu senti que ia dá tudo certo, porque eu tou aQui há uns doze dias e você vê bebê no capacete, bebê no respirador, bebê na sonda, uns Que a mãe não pode nem pegar. Eu tava podendo pegar, podia dá banho tem mais aparência, embora Que às vezes ela diminui um pouQuinho, aí eu me sentia fazendo alguma coisa para ajudar ela, tinha a certeza Que ela ia sair" (Maravilha).

Esse discurso verbaliza o resgate da maternidade, é como se por um determinado período, especialmente o de maior gravidade do neonato, esse filho pertencesse à equipe e, ao participar dos cuidados com ele na UTIN, a mãe resgata o seu papel maternal. Percebe-se então, Que o exercício da maternidade está vinculado ao cumprimento de certos esquemas comportamentais e sentimentais $^{(12)}$.

\section{Representações na comunicação eQuipe-mãe}

A internação do filho na UTIN é percebida pelos pais como algo assustador ${ }^{(13)}$. Nesse aspecto, surgem as dificuldades por eles enfrentadas no processo de comunicação com a eQuipe já revelada em estudos realizados com mães acompanhantes de filhos prematuros $^{(5,14)}$. Alguns autores consideram a comunicação entre médicos e os pais dos bebês um monólogo no Qual os profissionais falam e os pais escutam e acatam ${ }^{(15)}$. Essa situação é revelada na fala seguinte.

"Cada médico tem seu método de trabalho, cada enfermeiro também. Tem uns Que são mais agradáveis tem uns Que não são, mas dá pra levar. Tem uns profissionais Que não sabe chegar, você já ta ali, jogada mesmo as traças de sofrimento mesmo, mas vai dando certo a gente tem mais é Que aceitar e seguir de acordo com que mandam" (Petúnia).

No processo de comunicação repercute também o aspecto não verbal Que pode gerar conclusões não condizentes com a realidade. Essa situação pode ser identificada em momentos impactantes Que bloqueiam a escuta do significado das palavras e busca outros aspectos de comunicação com gestos e posturas comportamentais $^{(1)}$. Nessa perspectiva, as interpretações podem ser equivocadas conforme observada no relato a seguir.

“Às vezes eu Quero perguntar uma coisa e vejo alguns com a cara meio assim, trancada e penso Que vou ter uma resposta ruim, mas nem sempre assim Quem vê rosto não vê coração, então se a curiosidade é minha eu vou fundo que eu tenha uma resposta boa ou ruim, mas eu vou a fundo, é um direito meu" (Lírio).

Cabe destacar que a especialidade necessária aos profissionais 
das UTINs favorece o surgimento das relações hierárQuicas e de submissão ${ }^{(1)}$. O uso de termos técnicos não condizentes com o entendimento materno faz com Que os profissionais sejam percebidos como detentores do saber.

Assim, torna-se necessário que a equipe da UTIN acolha e exerça uma comunicação adeQuada com os pais para Que esses possam construir a realidade de ter um filho prematuro e amenizar seus conflitos em um cotidiano Que inclui as incertezas Quanto à sobrevivência do filho.

\section{Os sentimentos maternos vivenciados durante a hospitalização do filho na UTIN}

O nascimento de um filho prematuro causa nas mães reação de choque tanto pelo nascimento inesperado e mais freqüentemente pelo aspecto frágil de um bebê diferente da imagem daquele Que foi construída durante a gravidez. Essa percepção é geradora de insegurança para a família ${ }^{(16)}$, especialmente para a mãe.

A partir da situação de hospitalização do filho instala-se o momento de crise, no Qual a mãe é submetida a sentimentos de culpas por não ter sido capaz de levar a gravidez a termo. Comumente, a culpa também surge Quando ela julga ter feito algo de errado ${ }^{(3)}$.

Seqüencialmente, na primeira visita a UTIN a mãe se depara com um ambiente assustador Que acentua os sentimentos de insegurança e medo, por outro lado experimentam alegria e conformismo por constatar Que o filho está vivo e com possibilidades de sobrevivência diante dos recursos tecnológicos e especialidades dos profissionais Que compõe a UTIN. Essa ambigüidade de sentimentos foi observada no estudo de Lamy ${ }^{(13)}$ Que constatou Que mesmo o ambiente sendo assustador, a hospitalização tornase positiva Quando na perspectiva da recuperação do filho, conforme observado no relato seguinte:

"A UTI apesar de dá medo ela é importante porque o bebê precisa apesar de você ter medo. Você tem a noção de Que lá dentro toda a equipe dá amparo a seu filho. Você tem médico 24 horas acompanhando o seu filho, tem enfermeiros que cuidam. Você fica alegre de saber que ta sendo feito tudo pra ele sobreviver. Ter os aparelhos que eles precisam e os profissionais que sabem cuidar dele, dá uma aliviada" (Violeta).

Superada a crise inicial, no cotidiano da UTIN, os sentimentos tendem a mudar após alguns dias de internação especialmente Quando as mães constatam a evolução clínica do filho e passam a interagir executando cuidados específicos como troca de fraldas, oferecer dieta e, sobretudo, segurar o bebê no colo.

Porém, o processo de adaptação da mãe a hospitalização do filho parece receber influência de fatores externos como social, cultural e familiar. As histórias de vida, as experiências diferentes, refletem nos sentimentos e atitudes Que variam de pessoa a pessoa ${ }^{(4)}$. Agrega-se a isso a Qualidade da assistência fornecida pela equipe e a forma como esta possibilita as mães a expressar seus sentimentos e falar de suas angústias medos e ansiedades. Neste contexto a equipe de enfermagem pode aliviar as sensações dolorosas da família em relação ao seu filho e fortalecer o vínculo mãe-bebe ${ }^{(3)}$.

\section{CONSIDERAÇÕES FINAIS}

A hospitalização do filho na UTIN é representada inicialmente pela Quebra do simbolismo tradicional do nascimento seguida de situações difíceis e conflitantes entrelaçadas ao desafio de adeQuação à rotina estressante da UTIN e os percalços inerentes à trajetória na busca da sobrevivência do filho. Nesta vivência, inserem-se sentimentos como choque, culpa insegurança, medo, tristeza, alegria e esperança.

A partir dessas constatações, observa-se que os profissionais de saúde atuantes em UTIN, precisam agir com sensibilidades, ter disponibilidade para escuta e possibilitar o diálogo com a família de prematuros e, principalmente com as mães, de forma a favorecer a adequação progressiva da mãe à realidade do nascimento e hospitalização de um filho prematuro.

Nesse contexto, percebe-se a necessidade de uma nova abordagem no atendimento neonatal, na Qual deverão ser contemplados não apenas os aspectos das necessidades fisiológicas do prematuro, mas especialmente aqueles ligados ao atendimento dos fatores emocionais Que envolvem os pais nos momentos das fragilidades presentes nas situações de prematuridade.

\section{REFERÊNCIAS}

1. Guimaraes GP, Moticelli M. A formação do apego pais/recémnascido pré-termo e/ou de baixo peso no método mãe-canguru: uma contribuição da enfermagem. Texto Contexto Enferm 2007; 16(4): 626-35.

2. Sales CA, Alves NB, Vrecchi MR, Fernandes I. Concepções das mães sobre os filhos prematuros em UTI. Rev Bras Enfermagem 2006; 59(1): 20-4.

3. Fraga ITG, Pedro ENR. Sentimentos das mães de recémnascidos prematuros: implicações para a enfermagem. Rev Gaúcha Enferm 2004; 25(1): 89-97.

4. Mittag BF, Wall ML. Pais com filhos internados na UTI neonatal - sentimentos e percepções. Fam Saúde Desenv 2004; 6(2): 134-45.

5. Vasconcelos MGL, Leite AM, Scochi CGS. Significados atribuídos à vivência materna como acompanhante do recémnascido pré-termo e de baixo peso. Rev Bras Saúde Matern

Infant 2006; 6(1): 47-57.

6. Scochi CGS. A humanização da assistência hospitalar ao bebê prematuro: bases teóricas para o cuidado de enfermagem [tese]. Ribeirão Preto: Escola de Enfermagem de Ribeirão Preto, Universidade de São Paulo; 2000.

7. Minayo MCS. Pesquisa social: teoria, método e criatividade. $10^{\mathrm{a}}$ ed. Petrópolis: Vozes; 1994.

8. Bardin L. Análise de conteúdo. Lisboa: Edições 70; 2000.

9. Valansi L, Morsch DS. O psicólogo como facilitador da interação familiar no ambiente de cuidados intensivos neonatais. Psicol Ciência Profissão 2004; 24(2): 11 2-19.

10. Costernaro RGS, Martins DA. Qualidade de vida do recémnascido internado em UTI: as relações mãe-filho. Cogitare Enferm 1988; 3(2): 56-9.

1 1. NieweglowskiV H, Moré CLOO. Comunicação equipe- família em Unidade de terapia intensiva pediátrica: impacto no processo 
de hospitalização. Estudo de Psicologia 2008; 25(1): 1 I I-22.

12. Santos, MFS, Novelino AM, Nascimento AP. O mito da maternidade: discurso tradicional sob roupagem modernizante. In: Moreira ASP, organizadores. Representações sociais: Teoria e prática. João Pessoa: Editora da UFPB; 200 I . p. 269-293.

13. Lamy ZC, Gomes R, Carvalho M. A percepção dos pais sobre a internação de seus filhos em unidade de terapia intensiva neonatal. I Pediatria 1997; 73(5): 293-8.

14. Souza NL, Araújo ACPF, Azevedo GD, Jerônimo SMB, Barbosa LM, Sousa NML. Percepção materna com o recém nascido prematuro e vivência da gravidez com pré-eclâmpsia. Rev Saúde
Pública 2007; 41 (5): 704-10.

15. Gaiva MAM, Scochi CGS. A comunicação entre a eQuipe e os pais em uma UTI neonatal de um hospital universitário. In: Anais do $8^{\circ}$ Simpósio Brasileiro de Comunicação em Enfermagem; 2002 maio 2-3; São Paulo(SP), Brasil. [citado em 15 fev 2009]. Disponível em: http://www.proceedings. scielo.br/scielo.php

16. Tronchin DMR, Tsunechiro MA. A experiência de tornarem-se pais de prematuros um enfoque etnográfico. Rev Bras Enferm 2005; 58 (I): 49-54. 